\title{
Interrelation between Rheumatic Autoimmune Disease, Autohemolitic Anemia and Cancer Arising as Epiphenomenon on Paraneoplastic Syndrome
}

\author{
Dejan Spasovski $^{1 *}$, Emilija Sandevska ${ }^{1}$, Svetlana Krsetvska-Balkanov ${ }^{2}$ \\ ${ }^{1}$ University Clinic for Rheumatology, Clinical Center "Mother Therese”, Skopje, Republic of North Macedonia. \\ ${ }^{2}$ University Clinic of Hematology, Clinical Center "Mother Therese", Skopje, Republic of North Macedonia.
}

*Corresponding Author: Dejan Spasovski, University Clinic of Rheumatology, University Clinical Center - Mother Therese, Skopje, Republic of North Macedonia.

\section{Received Date: 23 August 2021 | Accepted Date: 12 November 2021 | Published Date: 23 November 2021}

Citation: D Spasovski, E Sandevska, Svetlana K Balkanov. (2021). Multiple Sclerosis and Chlamydia. International Journal of Clinical Case Reports and Reviews. 9(1); DOI:10.31579/2690-4861/169

Copyright: () 2021 Dejan Spasovski, This is an open-access article distributed under the terms of the Creative Commons Attribution License, which permits unrestricted use, distribution, and reproduction in any medium, provided the original author and source are credited.

Abstract
There are hemolytic anemias of different origin. For instance, these states may be induced by means of some exogenic
hemolytic factors: by different organic and unorganic hemolytic toxins (phosphorus, phenylhydrazin, saponins,
arsenicum, lead and biotoxins - snake venom, mushroom poisons, mycotoxins, etc.), some medical preparations,
radiations, some infectious agents and haevy burns. Besides, in some cases, hemolytic anemias are induced by
antibodies and immunocompetent cells against own tissues (autoimmune hemolytic anemia).
Keywords: rheumatic autoimmune disease; autohemolitic anemia; cancer; epiphenomenon; paraneoplastic
syndrome

\section{Introduction}

There are hemolytic anemias of different origin. For instance, these states may be induced by means of some exogenic hemolytic factors: by different organic and unorganic hemolytic toxins (phosphorus, phenylhydrazin, saponins, arsenicum, lead and biotoxins - snake venom, mushroom poisons, mycotoxins, etc.), some medical preparations, radiations, some infectious agents and haevy burns. Besides, in some cases, hemolytic anemias are induced by antibodies and immunocompetent cells against own tissues (autoimmune hemolytic anemia).

Reason of immunization of autoimmune hemolytic anemias may be some infection diseases (malaria, grippe, pneumonias, i.e. viruses, bacteria, acute anaerobic or streptococcal sepsis, mycoplasma pneumoniae,) and some chemical and physical factors and influences.

There is a relationship between B-cell oncogenesis and autoimmunity disease.

According to clinical studies malignant tumors in autoimmune hemolytic anemias appear in $45-47 \%$. Observation of a large body of literature, permit to suggest that quite frequently tumor cells in autoimmune hemolytic anemias have lymphoid and macrophagal nature. The analysis of 234 patients with autoimmune hemolytic anemias showed chronic lympholeukemias, malignant lymphomas, multiple myelomas, alimentary tract cancers and so on [1]. The analysis of 168 patients with hemolytic anemias showed approximately similar results [2]. The incidence of tumors of this localization and histogenesis increases significantly during such human autoimmune diseases as systemic lupus erythematosus, rhematoid arthritis, etc. [3-5].

Some viruses, like grippe, rubella, HIV, and some carcinogenic agents can induce fussion and at the soma time cytolitic effect in somatic cell [6, 7].

For instance, toxin of Aspergillus flavus - aflatoxin, together with heavy toxic action, induces malignant tumors (hepatomas) of the liver. Such different effects of these agents on somatic cells possibly depend on the size of plasma membranes' pores induced by them.

For instance, high doses of carcinogenic agents lead to partial increasing of quantity of giant polynuclear cells, but further increase of this dose induces massive cellular lysis. In low doses of carcinogenic agents, dikaryons (cells, with comparatively high oncogenic potency) are observed most frequently.

Larger perforations induce considerable destruction of cell membranes and following cytolysis together with the perishing of these cells [8].

There are some assumptions about the association of Vipera lebetina bites with the development of cancer of different localization and histogenesis. For instance, after bite of snake with hemolytic action of venom (Vipera 
lebetina, Vipera Russellii, etc.) together with massive destruction of erythrocytes hemolysis. Some Fungus toxins, like Aspergillus ochraceus, Aspergillus flavus, Penicillium islandicum, may give some similar action.

In our opinion, the mechanism of malignant transformation in autoimmune reactions can be based on the inclusion of immunocompetent cells in different cellular cooperations, which is their normal physiological property.

As it is shown, in case of autoimmune hemolytic anemia or allotransplantations, the macro organism reacts to the modificated (foreign) cells by development of humoral and cellular immune responses (immune cytolysis). In the development of cytolysis the most important roles are played by specific antibodies and T-killer (cytotoxic) cells (immune effectors). 1. Antibody molecules have 2 main functions: they bind to the immunogenic antigens and after interaction with these antigens, initiates involvement of different cells and molecules. The constant region ( $\mathrm{C}$ region) of the antibodies defines the type of the response after the antibody-antigen interaction, whether this is complementmediated lysis, cellular cytotoxicity, enhanced phagocytosis, etc. 2. The cell-immune cytolysis is carried out directly by the killers (T-cytotoxic cells).The cytotoxic effect of these cells is realized in the target cells plasmalemma by special proteins - perforins which lead to the formation in this organoid. This cells generate substances of cytotoxic and cytolytic action, causing thus cell necrosis with disintegration of its plasmalemma or induction of apoptosis. Perforins (together with granzymes and granulolyzins) are localized in killer cells (macrophages, T-lymphocytes, NK-cells) granules. In the presence of calcium, perforines interact with the plasmatic membrane of the target cells and after the polymerization they are forming the transmembrane channels (pores) in this organoid. In the case of great number or size, these pores induce the cells destruction or other cytopathogenic effects. So both, cytotoxic cells and antibodies can induce damages of some degree plasma membranes in somatic cell. This condition can represent as precancerous state and later the true cancerous cells formation $[9,10]$.

Target cell killing is carried out in several phases: 1) contact with killertarget-cell; 2) activation on killer cell; 3) killer cell make exocytosis of this toxic substances; and 4) toxic effect directed on target cell. Thus, pore-forming enzyme, antibodies, peptids, etc. cause plasma membrane damage in target cells, with consequences as diverse as proliferation or cell destruction.

Supposing that leucocytes (in this concrete case, lymphocytes and macrophages) are phenotypically dominant cells, their fusion with each other and with other somatic cells may lead to tumor formation of lymphoid and macrophagal nature. Carcinogenic agents and even infectious viruses and bacterial membranotoxins may induce both fusion and hemolytic effects in somatic cells simultaneously. In autoimmune hemolytic anemias side by side with hemolysis it may take place process of somatic cells fusion with further formation of tumor cells.
Thus, cell fusion may in some cases of autoimmune process produce a cell with tumor properties. Carcinogenic agents or some other reasons (immunocompetent cells, antibodies) may create the autoimmunization background in a macro organism, which may lead to multiple intercellular contacts between immunocompetent cells and cells with aberrant antigens. In case of cells fusion, initiation of malignant neoplasms of lymphoid or macrophagal histogenesis is expected to take place.

As a possible cellular mechanism of malignization in hemolytic anemias of different origin is proces of fusion of immunocompetent cell with other ones.

All the more that, formation of hybrid cells in vivo, it is possible consider as an physiological phenomenon.

\section{References}

1. Batailler ER, Klein B, Durie BGM, et al. (1989). Interrelationship between autoimmunity and B-lymphoid cell oncogenesis in humans. Clin. Exp. Rheumatol. 7:319-328.

2. Lechner K, Obermeier HL. (2012). Cancer-related microangiopathic hemolytic anemia: clinical and laboratory features in 168 reported cases. Medicine (Baltimore). 91:195205.

3. Bernatsky S, Ramsey-Goldman R, Rajan R, et al. (2005). NonHodgkin's lymphoma in systemic lupus erythematosus. Ann. Rheumatol. Dis. 64:1507-1509.

4. Bernatsky S, Ramsey-Goldman R, Clarke AE. (2009). Malignancy in systemic lupus erythematosus: what have we learned? Best Pract. Res. Clin. Rheumatol. 23(4):539-547.

5. Landgren AM, Landgren O, Gridley G, et al. (2011). Autoimmune disease and subsequent risk of developing alimentary tract cancers among 4, 5 million US male veterans. Cancer. 117(6):1163-1171.

6. Vaananen P, Kaarianen L. (1980). Fusion and hemolysis of erythrocytes caused by three togaviruses: Semliki Forest, Sindbis and Rubella. J. Gen. Virol. 46:467-475.

7. Huang RT, Rott R, Klenk HD. (1981). Influenza viruses cause hemolysis and fusion of cells. Virology. 110:243-247.

8. Gogichadze GK, Misabishvili EV, Gogichadze TG. (2006). Tumor cells formation by normal somatic cells fusion and cancer prevention prospects. Med Hypotheses. 66(1):133-136.

9. Gogichadze GK, Gogichadze TG. (2010). Karyogamic theory of cancer cell formation from the view of the XXI century. Nova Biomedical Books, New York.

10. Gogichadze GK, Gogichadze TG, Kamkamidze GK. Presumably common trigger mechanism of action of diametrically different carcinogens on target cells. Cancer and Oncology Research. 1(2):65-68. 